\title{
Analisis Video Comments to Video Likes Ratio Instagram Pada Top 5 Raksasa Teknologi di Dunia
}

\author{
I PUTU GEDE WIDYADNYANA (19101370) \\ Iputugedewidadnyana@gmail.com
}

\begin{abstract}
Instagram is a photo and video sharing application that allows users to take photos, take videos, apply digital filters, and share them on various social networking services, including Instagram's own. One unique feature on Instagram is cropping photos into square shapes, so they look like the results of Kodak Instamatic and Polaroid cameras. This is different from the $4: 3$ or $16: 9$ aspect ratio commonly used by cameras on mobile devices. Instagram can be used on any iPhone, iPad or iPod Touch with iOS 7.0 or later operating system, any Android mobile phone with operating system version 2.2 (Froyo) and above, and Windows Phone 8. This application can be downloaded via the Apple App Store and Google Play. On April 9, 2012, it was announced that Facebook had agreed to take over Instagram for approximately \$1 billion. Instagram that is active in the world provides benefits for many people, as well as a company. Instagram as a social media marketing platform. We took a sample of 5 tech giants in the world that use Instagram accounts as a marketing platform, namely: Apple, Facebookapp, Google, Microsoft, Amazon. The purpose of this study is to calculate the credibility of the performance of the 5 Rasasa Teknologi Dunia Instagram account. The method used for this research is quantitative exploratory method. The results of this study indicate that Apple's Instagram account is ranked first and has good account performance credibility.
\end{abstract}

\footnotetext{
ABSTRAK

Instagram adalah aplikasi berbagi foto dan video yang memungkinkan pengguna untuk mengambil foto, mengambil video, menerapkan filter digital, dan membagikannya ke berbagai layanan jejaring sosial, termasuk milik Instagram. Salah satu fitur unik di Instagram adalah cropping foto menjadi bentuk persegi, sehingga terlihat seperti hasil kamera Kodak Instamatic dan Polaroid. Ini berbeda dengan rasio aspek 4:3 atau 16:9 yang biasa digunakan oleh kamera di perangkat seluler. Instagram dapat digunakan di iPhone, iPad, atau iPod Touch apa pun dengan sistem operasi iOS 7.0 atau yang lebih baru, ponsel Android apa pun dengan sistem operasi versi 2.2 (Froyo) ke atas, dan Windows Phone 8. Aplikasi ini dapat diunduh melalui Apple App Store dan Google Play. Pada tanggal 9 April 2012, diumumkan bahwa Facebook telah setuju untuk mengambil alih Instagram untuk sekitar \$ 1 miliar.
} 
Instagram yang aktif di dunia memberikan maanfaat bagi banyak orang, maupun suatu perusahaan. Instagram sebagai platform social media marketing. Kami megambil sampel 5 Raksasa teknologi di dunia yang memanfaatkan akun Instagram sebagai salah satu platform pemasaran, yaitu : Apple, Facebookapp, Google, Microsoft, Amazon. Tujuan dari penelitian ini yaitu untuk menghitung kredibilitas dari performa akun Instagram 5 Rasasa Teknologi Dunia. Metode yang digunakan untuk penelitian ini yaitu metode eksploratif kuantitatif. Hasil dari penelitian ini menunjukan bahwa akun Instagram Apple mendapatkan peringkat pertama dan memiliki kredibilitas performa akun yang baik.

Keyword : Credibility Account Instagram ;Social Media Marketing ; Social Media Instagram;

\section{PENDAHULUAN}

Teknologi telah berkembang dengan pesat pada zaman revolusi industry 4.0 bidang teknologi banyak digunakan untuk keperluan industry. Penggunaan akan perangkat teknologi seperti komputer, smartphone atau tablet mengalami peningkatan yang sangat tinggi. Hal tersebut juga berbanding lurus dengan kebutuhan akan jaringan internet. Banyak hal yang dapat dilakukan, dan media sosial adalah salah satu fitur yang paling sering digunakan oleh pengguna internet saat ini.

Media sosial adalah media daring yang digunakan untuk kebutuhan komunikasi jarak jauh, proses interaksi antara user satu dengan user lain, serta mendapatkan sebuah informasi melalui perangkat aplikasi khusus menggunakan jaringan internet. Tujuan dari adanya social media sendiri adalah sebagai sarana komunikasi untuk menghubungkan antar pengguna dengan cakupan wilayah yang sangat luas. Agar pengguna media sosial (medsos) lebih mudah dan cepat, dibutuhkan koneksi internet yang stabil dan cepat. Anda tidak perlu lagi menghubungi orang lain melalui kabel telepon atau alat komunikasi tradisional. Cukup dengan mengakses media sosial, anda dapat terhubung dengan banyak orang, membuat forum, diskusi bersama, mengunggah aktivitas keseharian anda, dan lain sebagainya. (Adani, 2020).

Contoh aplikasi sosial media yang memiliki banyak pengguna saat ini yaitu Instagram. Instagram adalah sebuah aplikasi berbagi foto dan video yang memungkinkan pengguna mengambil foto, mengambil video, menerapkan filter digital, dan aktivitas berjejaring lainnya. Pada 9 April 2012, Facebook resmi mengambil alih Instagram senilai hampir \$1 miliar dalam bentuk tunai dan saham. Logo dari Instagram sendiri berupa kamera polaroid yang menggambarkan sebuah aplikasi berbagi foto dan video instan. 
Maraknya jumlah pengguna Instagram aktif di dunia tentu dapat memberikan peluang bagi brand untuk menjadikan platform ini sebagai platform social media marketing. Cukup banyak akun perushaan-perusahaan terkenal yang ada pada Instagram, contohnya seperti teknologi di dunia. Adapun Top 5 Raksasa Teknologi di Dunia, diantaranya yaitu : Apple, Facebookapp, Google, Microsoft, Amazon. Penelitian ini menggunakan metode eksploratif kuantitatif, dan akan menghitung menggunakan rasio-rasio yang ada pada Instagram. Pada penelitian menjelaskan bahwa terdapat 8 rasio yang ada pada sosial media Instagram dan relevan digunakan sebagai media ukur kredibilitas akun yang ada. Penelitian ini hanya berfokus untuk menghitung kredibilitas Video Comments to Video Likes Ratio pada Top 5 Raksasa Teknologi di dunia. Tujuan dari penelitian ini adalah mengetahui kredibilitas performa dari akun Instagram Top 5 Raksasa Teknologi di dunia menggunakan Video Comments to Video Likes Ratio.

\section{TINJAUAN PUSTAKA}

Saat ini pengguna media sosial telah mencapai angka 3,6 miliar dan setiap harinya akan terus meningkat. Sepanjang tahun 2020 mulai bulan maret, masyarakat dunia banyak menghabiskan waktunya di rumah karena adanya pandemi COVID-19. Menurut laporan dari statista, hal tersebut berdampak pada naiknya penggunaan media sosial hingga $21 \%$ dalam periode bulanan. Selama periode tersebut, pengguna media sosial tidak hanya menggunakan platform sosial untuk berinteraksi dengan pengguna lain, tetapi mereka juga memanfaatkannya untuk meriset produk, sarana hiburan, mencari berita teraktual dan sebagainya. Tak heran jika saat ini media sosial menjadi salah satu tempat yang praktis dan cepat dalam memperoleh segala informasi terbaru yang ada di seluruh dunia. (admin, 2021).

Media baru alias media sosial sudah menjadi tempat mengungkapkan amarah, kebencian, caci maki, penghinaan, cyber bullying, dan proses komunikasi dalam kategori antikomunikasi lainnya. Tidak terbatas pada masalah politik, dan sosial, juga pada masalah agama, SARA, bahkan masalah pribadi sekalipun turut meramaikan ruang dimedia sosial terkhususnya di INSTAGRAM. Berbagai berita yang muncul di beranda instagram. instagram juga terdapat banyak bisnis-bisnis online, seperti olshop dll. Sehingga memberi peluang bagi konsumen tertarik pada barang tersebut. Apa yang berkembang di media sosial belakangan ini mungkin dapat disebut sebagai kecenderungan proses berkomunukasi dalam kategori antikomunikasi. (Afifahfaradhila, 2020). 
Pada hari pertama kemunculannya, Instagram langsung disambut oleh banyak orang. Tercatat sekitar 10-25 ribu orang mengunduh dan menjadi pengguna Instagram. Angka ini terus meningkat menjadi ratusan ribu pada bulan-bulan berikutnya. Bahkan dalam kurun satu tahun, angkanya menembus 10 juta. Terus meningkatnya angka pengguna, membuat banyak orang memprediksi bahwa Instagram akan menjadi aplikasi terbaik di masa depan. Namun kekurangan pada pengelolaan internal Instagram inilah yang membuat Facebook melirik Instagram untuk pertama kalinya. Akhirnya, usai negosiasi panjang, keduanya mencapai kata mufakat. Pada April 2012, Facebook resmi mengakuisisi Instagram senilai \$ 1 Miliar. Dan kelak, ucapan Systrom tersebut terbukti ketika Facebook memainkan peran penting dalam melakukan perubahan di Instagram. "Dari menjalankan perusahaan rintisan ada bagian menyenangkan dan bagian yang tidak terlalu menyenangkan. Facebook menangani bagian yang tidak terlalu menyenangkan: seperti infrastruktur, spam, dan penjualan,” kata Systrom kepada Guardian. (Fakhriansyah, 2021)

Aplikasi Instagram tidak hanya digunakan untuk membuat konten foto/video dengan tujuan menghibur pengguna lainnya. Aplikasi Instagram juga dapat dijadikan peluang bagi brand atau perusahaan sebagai platform social media marketing. Penelitian menyatakan bahwa TikTok berpengaruh positif dan signifikan terhadap minat beli atau berbelanja secara online. Sehingga dengan ini, Instagram mampu memberikan peluang yang sangat tinggi bagi perusahaan-perusahaan dalam melakukan digital marketing. Instagram dirasakan memiliki kekuatan ataupun pengaruh dalam industri, sehingga menimbulkan kualitas akun yang menentukan strata maupun kredibilitas pemilik akun. Kredibilitas akun Instagram merupakan suatu hal yang cukup penting untuk berbagai kepentingan. Kredibilitas sebuah akun Instagram dapat diukur dari tingkat performa yang dihasilkan secara matematis. Dalam mengukur performa diperlukan skala pengukuran yang tertuang ke dalam rasio.

\section{METODE PENELITIAN}

Penelitian ini menggunakan metode eksploratif kuantitatif untuk mengetahui kredibilitas dari performa akun Instagram Top 5 Raksasa Teknologi di dunia. Penelitian Eksploratif merupakan studi dengan melakukan penelusuran, terutama dalam pemantapan konsep yang akan digunakan dalam ruang lingkup yang penelitian yang lebih luas dengan jangakauan konseptual yang lebih besar (Yusuf, 2017). Dalam melakukan eksplorasi, konsep yang matang menjadigoal dalam penelitian dan jangakauan konseptual yang lebih 
luas. Penelitian eksploratif merupakan penelitian awal yang bertujuan untuk mendapatkan gambaran mengenai suatu topik penelitian yang akan diteliti lebih jauh (Humas, 2018)

Tujuan dari penelitian ini yaitu mengetahui nilai kredibillitas dari performa akun Instagram Top 5 Raksasa Teknologi di dunia. Langkah - Langkah yang dilakukan untuk penelitian ini sebagai berikut.

\section{Melakukan penelusuran Pada Website untuk menganalisa objek}

Eksplorasi ini dilakukan di berbagai sistus website, kami menelusuri beberapa situs lalu memilah informasi yang dibutuhkan untuk diteliti. Setelah informasi yang didapatkan cukup, sehingga ditemukan nama-nama Top 5 Raksasa Teknologi di dunia yang akan dijadikan objek analisa. Setelah eksplorasi selesai, langkah selanjutnya mencari nama akun Instagram dari masing-masing Top 5 Raksasa Teknologi Dunia.

\section{Menghitung Nilai Rata-Rata Variable Dari Top 5 Raksasa Teknologi di dunia.}

Pada langkah ini, peneliti menghitung nilai variable video comments dan variable video likes. Variabel adalah suatu atribut, atau obyek yang mempunyai nilai variasi tertentu yang Untuk menghitung nilai rata-rata dari variabel video comments dan variabel video views yaitu mengambil minimal 10 postingan kemudian di hitung sehingga menemukan nilai rata-rata dari masing-masing variabel. 


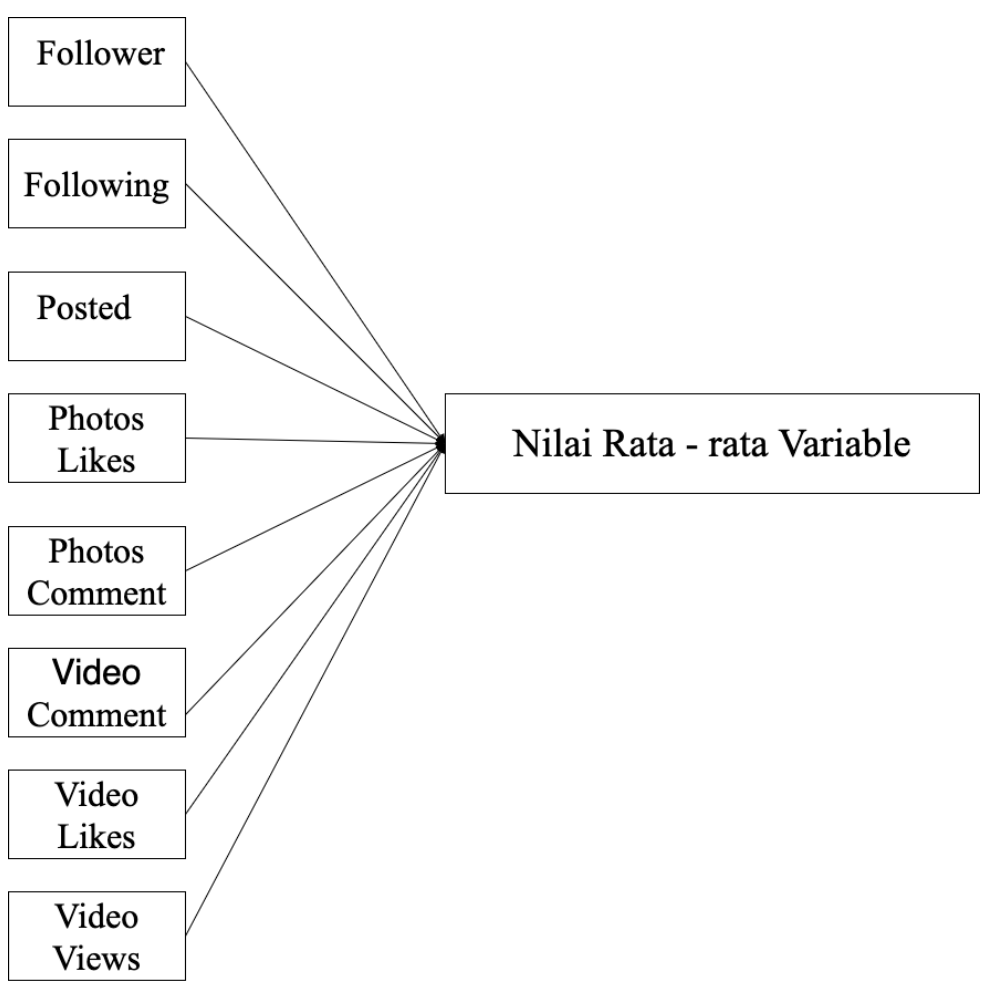

Gambar 1 : Analisa nilai Rata - rata Variable

\section{Menghitung Nilai Kredibilitas Rasio}

Untuk menghitung nilai kredibilitas dari video comments to video likes ratio, peneliti menggunakan cara membagi nilai variabel pertama dengan nilai variabel kedua. Jika video comments memiliki nilai 100 dan video likes memiliki nilai 300, maka cara menghitungnya yaitu $100: 300=0,3$. Dengan begitu nilai dari video comments to video likes ratio adalah 0,3 .

\section{Menentukan Peringkat Pada Akun Instagram}

Pada langkah terakhir yang dilakukan pada penelitian ini yaitu menentukan peringkat pada masing-masing rasio yang ada. Pada penentuan peringkat perlu melihat karakteristik dari rasio yang di teliti. Jika karakteristik rasio merupakan rendah, maka objek yang memiliki nilai terendah akan mendapatkan angka 5 dan objek yang memiliki nilai tertinggi akan mendapatkan angka 1. Namun jika rasio memiliki karakteritik tinggi maka objek yang mendapatkan nilai tinggi akan mendapatkan angka 5 dan objek yang mendapatkan nilai terendah akan mendapatkan angka 1. Setelah mendapatkan hasil kredibilitas ratio maka dapat disimpulkan objek yang mana mendapatkan peringkat 1 sampai dengan peringkat 5 . 


\section{HASIL DAN PEMBAHASAN}

Akun Instagram Dari 5 Raksasa Teknologi Dunia di 2021, diantaranya :

\section{Apple}

Instagram Q Cari

$\Lambda \oplus \oplus \oplus 0$
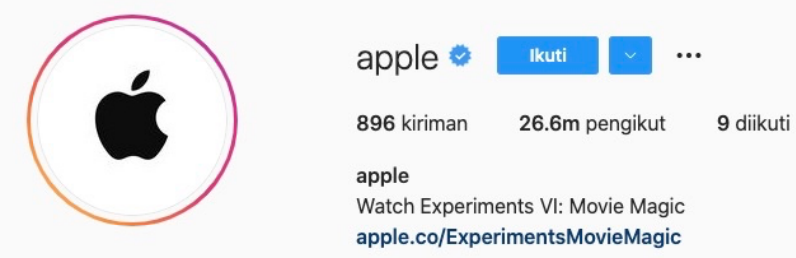

Sumber : https://www.instagram.com/apple/?hl=id (akses pada 22-10-2021)

\section{Google}

Instagram

Q Cari

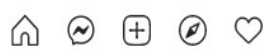
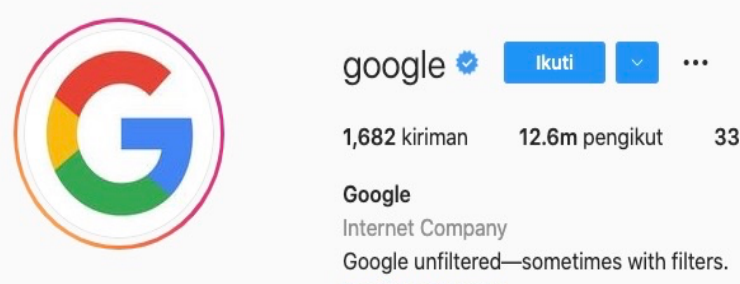

Dilikuti oleh jungayik, 1windyoung, arijayaa, + 10 lainnya

Sumber : https://www.instagram.com/google/?hl=id (akses pada 22-10-2021)

\section{Facebookapp}

Instagram

a cari

$\Omega \oplus \oplus \oplus 0$
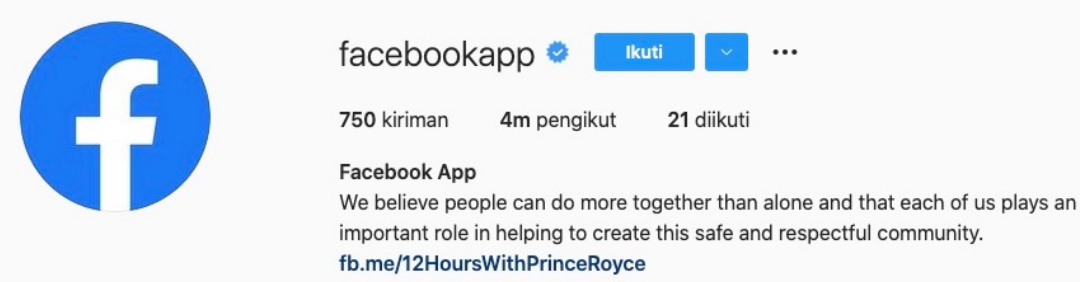

Sumber : https://www.instagram.com/facebookapp/?hl=id (akses pada 22-10-2021) 


\section{Microsoft}

Instagram

a car

$\Omega \oplus \oplus \oplus \infty$
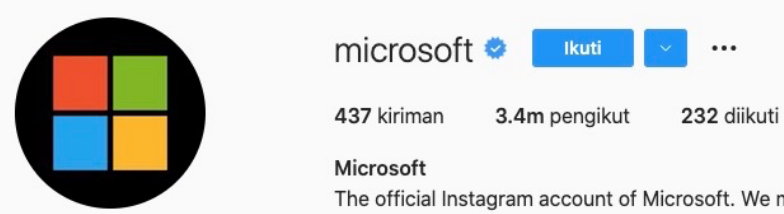

Sumber : https://www.instagram.com/microsoft/?hl=id (akses pada 22-10-2021)

\section{Amazon}

Instagram

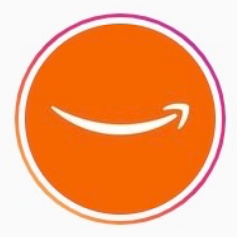

凡 $\oplus \oplus 0$

Sumber : https://www.instagram.com/amazon/?hl=id (akses pada 22-10-2021)

Terdapat 5 akun media social Instagram raksasa teknologi dunia 2021, dari kelima akun tersebut peneliti menemukan beberapa variable dan nilai dari masing - masing variable untuk menghitung rasio Video Comment to Video Likes dari kelima akun Instagram raksasa teknologi dunia. Terdapat 8 variable pada Instagram yaitu :

1. Follower

2. Following

3. Posted

4. Photos Like

5. Photos Comment

6. Video Viewers

7. Video Comment

8. Video Like

Dari kedelapan variable tersebut peneliti hanya memfokuskan pada penilaian variable Video Comment dan Video Likes.

1. Video Comment

2. Video Likes 
Dari kedua variable tersebut dapat dianalisa untuk menemukan nilai rata - rata dari variable Video Comment dan nilai rata - rata Variable Video Likes. Cara menganalisa akun Instagram tersebut adalah dengan menghitung nilai rata - rata dari variable Video Comment dan Variable Video Likes lalu mengambil minimal 10 postingan Video pada akun Instagram tersebut. Sehingga enemukan hasil nilai rata - rata pada kelima akun Instagram raksasa teknologi dunia.

Berikut kami cantumkan kelima table nilai rata - rata dari masing - masing akun Instagram raksasa teknologi dunia 2021.

Table 1. Analisis nilai rata - rata nilai variable Video Comment to Video Like akun Instagram apple

\begin{tabular}{|l|l|l|}
\hline \multicolumn{3}{|c|}{ Apple } \\
\hline NO & Video Comment & Video Likes \\
\hline 1 & 1.791 & 285.609 \\
\hline 2 & 1.585 & 331.638 \\
\hline 3 & 533 & 102.745 \\
\hline 4 & 701 & 87.528 \\
\hline 5 & 5.409 & 406.093 \\
\hline 6 & 1.246 & 124.036 \\
\hline 7 & 1.323 & 357.065 \\
\hline 8 & 700 & 66.248 \\
\hline 9 & 352 & 67.340 \\
\hline 10 & 765 & 197.392 \\
\hline Rata - rata & 1.441 & 203.145 \\
\hline
\end{tabular}

Sumber : Pengolahan Data Excel

Table 2. Analisis nilai rata - rata nilai variable Video Comment to Video Like akun Instagram Google

\begin{tabular}{|l|l|l|}
\hline \multicolumn{3}{|c|}{ Google } \\
\hline NO & Video Comment & Video Likes \\
\hline 1 & 187 & 11.896 \\
\hline 2 & 496 & 13.301 \\
\hline 3 & 1227 & 48.930 \\
\hline
\end{tabular}




\begin{tabular}{|l|l|l|}
\hline 4 & 572 & 22.256 \\
\hline 5 & 349 & 30.818 \\
\hline 6 & 253 & 14.954 \\
\hline 7 & 596 & 19.163 \\
\hline 8 & 281 & 12.206 \\
\hline 9 & 390 & 11.966 \\
\hline 10 & 129 & 11.402 \\
\hline Rata - rata & 448 & 20.610 \\
\hline
\end{tabular}

Sumber : Pengolahan Data Excel

Table 3. Analisis nilai rata - rata nilai variable Video Comment to Video Like akun Instagram

\section{facebookapp}

\begin{tabular}{|l|l|l|}
\hline \multicolumn{3}{|c|}{ Facebookapp } \\
\hline NO & Video Comment & Video Likes \\
\hline 1 & 122 & 2.677 \\
\hline 2 & 1.250 & 8.334 \\
\hline 3 & 212 & 2.032 \\
\hline 4 & 436 & 2.527 \\
\hline 5 & 208 & 2.243 \\
\hline 6 & 363 & 23.913 \\
\hline 7 & 63 & 1.678 \\
\hline 8 & 259 & 1.752 \\
\hline 9 & 238 & 1.603 \\
\hline 10 & 4.176 & 559.925 \\
\hline Rata - rata & 733 & 5.195 \\
\hline
\end{tabular}

Sumber : Pengolahan Data Excel

Table 4. Analisis nilai rata - rata nilai variable Video Comment to Video Like akun Instagram microsoft

\begin{tabular}{|l|l|l|}
\hline \multicolumn{3}{|c|}{ Microsoft } \\
\hline NO & Video Comment & Video Likes \\
\hline 1 & 47 & 4.411 \\
\hline
\end{tabular}




\begin{tabular}{|l|l|l|}
2 & 447 & 38.572 \\
\hline 3 & 116 & 5.654 \\
\hline 4 & 92 & 5.351 \\
\hline 5 & 381 & 26.723 \\
\hline 6 & 68 & 4.810 \\
\hline 7 & 407 & 17.735 \\
\hline 8 & 168 & 13.996 \\
\hline 9 & 96 & 13.198 \\
\hline 10 & 526 & 39.597 \\
\hline Rata - rata & 235 & 14.494 \\
\hline
\end{tabular}

Sumber : Pengolahan Data Excel

Table 5. Analisis nilai rata - rata nilai variable Video Comment to Video Like akun Instagram amazon

\begin{tabular}{|l|l|l|}
\hline \multicolumn{3}{|c|}{ Amazon } \\
\hline NO & Video Comment & Video Likes \\
\hline 1 & 249 & 2.000 \\
\hline 2 & 206 & 2.539 \\
\hline 3 & 844 & 4.095 \\
\hline 4 & 671 & 5.446 \\
\hline 5 & 616 & 14.729 \\
\hline 6 & 1.851 & 53.053 \\
\hline 7 & 1.336 & 35.527 \\
\hline 8 & 227 & 6.097 \\
\hline 9 & 1.714 & 28.853 \\
\hline 10 & 328 & 30.139 \\
\hline Rata - rata & 804 & 16.927 \\
\hline
\end{tabular}

Sumber : Pengolahan Data Excel

Setelah menghitung nilai rata -rata variable video comment to video likes 10 postingan video dari 5 akun Instagram raksasa teknologi dunia 2021 maka akan memukan hasil akhir nilai rata - rata variable Video comment to Video Likes

Table 6. Nilai akhir Variable Video Comment To video Likes pada 5 akun Instagram raksasa teknologi dunia 


\begin{tabular}{|c|l|l|}
\hline \multicolumn{3}{|c|}{ Tabel Nilai Masing-Masing Variable } \\
\hline Variable & Video Comment & Video Likes \\
\hline Apple & 1.441 & 203.145 \\
\hline Amazon & 804 & 16.927 \\
\hline Facebook & 733 & 5.195 \\
\hline Microsoft & 235 & $14-494$ \\
\hline Google & 448 & 20.610 \\
\hline
\end{tabular}

Sumber : Pengolahan Data Excel

Pada social media Instagram terdapat 8 rasio yang relevan digunakan untuk menghitung kredibilitas pada masing-masing akun Instagram . Tetapi pada penelitian ini kami hanya berfokus pada menghitung Video Comments to Video Likes Ratio. Cara untuk menghitung kredibilitas dari masing-masing akun Instagram setiap raksasa teknologi dunia 2021, peneliti menghitung dengan cara : variabel 1 dibagi dengan variabel 2, atau variable Video Comment dibagi Video Likes sehingga ditemukan hasil analisisa dari rasio tersebut.

Tabel 7. Hasil perhitungan atau pembagian Rasio Akun Instagram 5 Raksasa teknologi dunia 2021

\begin{tabular}{|c|l|}
\hline \multicolumn{2}{|c|}{ Table Ratio } \\
\hline Ratio & Video Comment to Video Likes ratio \\
\hline Apple & 0,00709346 \\
\hline Amazon & 0,04749808 \\
\hline Facebook & 0,14109721 \\
\hline Microsoft & 0,01621361 \\
\hline Google & 0,02173702 \\
\hline
\end{tabular}

Sumber : Pengolahan Data Excel

Video Comments to Video Likes Ratio memiliki karakteristik yang tinggi, artinya semakin tinggi nilai dari pembagian 2 variable tersebut maka semakin baik kredibilitas dari performa akun Instagram tersebut. Untuk memberikan peringkat pada masing-masing akun Instagram 
Raksasa Teknologi Dunia 2021 adalah, peneliti memberikan Rangking 1 kepada akun instagran raksasa teknologi dunia yang mendapatkan nilai tertinggi dan rangking 5 untuk akun instagran raksasa teknologi dunia yang mendapatkan nilai terendah. Berikut merupakan tabel urutan nilai yang dihasilkan oleh masing-masing akun Instagram.

\begin{tabular}{|l|l|}
\hline \multicolumn{2}{|c|}{ Table Peringkat } \\
\hline Ratio & Rangking \\
\hline Apple & 1 \\
\hline microsoft & 2 \\
\hline google & 3 \\
\hline amazon & 4 \\
\hline facebook & 5 \\
\hline
\end{tabular}

Sumber : Pengolahan Data Excel

\section{Kesimpulan}

Dari table perangkingan diatas kami menarik kesimpulan bahwa akun Instagram apple yang mendapat nilai tertinggi untuk ratio Video Comment to Video Likes. Dan akun Instagram facebokapp mendapat nilai terendah pada penelitian ini.

Jadi akun Instagram apple emiliki krediabilitas dan perfoma yang lebih baik dari yang lainya, tentu saja ini hal yang wajar mengingat apple adalah perusahaan terkaya kedua di dunia dan perusahaan paling berharga di dunia jadi sudah tidak diragukan lagi

1. Peringkat pertama diraih oleh Perusahaan Apple dengan nilai tertinggi yaitu 0.00709346

2. Peringkat kedua diraih oleh Perusahaan Google dengan nilai 0. 02173702

3. Peringkat ketiga diraih oleh Perusahaan Microsoft dengan nilai 0. 01621361

4. Peringkat keempat diraih oleh Perusahaan Amazon dengan nilai 0. 04749808

5. Peringkat kelima diraih oleh Perusahaan Facebook dengan nilai terendah yaitu 0 . 14109721 


\section{DAFTAR PUSTAKA}

Afifahfaradhila, N. (2020, Mei 21). 13Kompasnia. Retrieved from Eksistensi social dalam Instagram:

https://www.kompasiana.com/nurafifahfaradhila/5ec63ed0097f367e841350b2/eksiste nsi-sosial-remaja-dalam-instagram?page $=$ all

admin, p. (2021, 1 21). 8 Tren Perkembangan Media Sosial untuk Pemasaran Online di 2021. Retrieved from Bonum: https://www.bonum.id/blog/8-tren-perkembangan-mediasosial-untuk-pemasaran-online-di-2021

Fakhriansyah, M. (2021, Oktober 06). Kisah Instagram Menjadi Aplikasi Serba Bisa Setelah Dibeli Facebook Baca selengkapnya di artikel "Kisah Instagram Menjadi Aplikasi Serba Bisa Setelah Dibeli Facebook", https://tirto.id/gj2S. Retrieved from tirto.id: https://tirto.id/kisah-instagram-menjadi-aplikasi-serba-bisa-setelah-dibeli-facebookgj $2 \mathrm{~S}$

Ismi, T. (2021, June 01). Produknya Pasti Pernah Kamu Pakai, Ini 5 Raksasa Teknologi Dunia di 2021. Retrieved from Glints: https:/glints.com/id/lowongan/raksasa-teknologidunia/\#.YXq7ctZBw1I

Adani, M. R. (2020, November 19). Pengaruh Penggunaan Media Sosial dan Manfaat untuk Bisnis. Retrieved from Sekawan Media: https://www.sekawanmedia.co.id/mediasosial-untuk-bisnis/

Humas. (2018, May 27). Penelitian Eksploratif. Retrieved from Penalaran Unm: https://penalaran-unm.org/penelitian-eksploratif/ 